\title{
Does the type of disease-modifying drugs impact on the quality of life in patients with relapsing-remitting multiple sclerosis?
}

\author{
Amirreza Naseri ${ }^{1,2}$, Ehsan Nasiri ${ }^{1,2}$, Malihe Talebi $^{3}$, Kimia Karimi $^{4}$, Mahnaz Talebi ${ }^{4}$ \\ ${ }^{1}$ Student Research Committee, Tabriz University of Medical Sciences, Tabriz, Iran \\ 2Students' Neuroscience Research Center (SNRC), Tabriz University of Medical Sciences, Tabriz, Iran \\ ${ }^{3}$ Health Center of East Azerbaijan Province, Tabriz, Iran \\ ${ }^{4}$ Neurosciences Research Center (NSRC), Tabriz University of Medical Sciences, Tabriz, Iran
}

\begin{abstract}
Objective. Multiple sclerosis (MS) can cause serious physical and mental problems, which can affect patients' health-related quality of life ( $\mathrm{HQoL})$. The aims of this study are comparing oral and injection disease-modifying drugs (DMDs) in improving HQoL and researching the relations between demographic characteristics and HQL. Material and methods. This is a cross-sectional study of patients whit a lower degree of disability with relapsing-remitting multiple sclerosis. According to drug usage, we divide patients into two groups of oral and injection medications. After obtaining informed consent, multiple sclerosis quality of life-54 (MSQOL-54) questionnaire filled by patients.

Outcomes. 115 patients including 34 males and 81 females with the mean age of $33.06 \pm 8.68$ years old were involved in this study. There was no significant difference in demographics factors between two groups. We observed no statistically significant difference between two groups of patients, but oral medicines showed a better function in physical health composite and users of injection DMDs were better in mental health composite. There was a negative correlation between age and the expanded disability status scale score with physical health composite, while education had a positive correlation with physical health composite. Except cognitive function, there wasn't any significant gender differences in any subscale of HQoL.

Conclusions. Oral and injection DMDs have a similar function in boosting HQoL in a lower degree of disability RRMS patients. Severity of the disease, education and age are related to health condition of MS patients
\end{abstract}

Keywords: multiple sclerosis, quality of life, pharmaceutical preparations, disease-modifying drugs

\begin{abstract}
Abbreviations
MS - multiple sclerosis

RRMS - relapsing-remitting multiple sclerosis

QoL - quality of life

HQoL - health-related quality of life

DMDs - disease-modifying drugs

EDSS - expanded disability status scale

MSQOL-54 - multiple sclerosis quality of life-54
\end{abstract}

\section{INTRODUCTION}

Multiple sclerosis (MS) is the most prevalent chronic inflammatory disease of the central nervous system [1] and the most common cause of neurological disability in young adults worldwide [2].
More than 2 million people all around the world have MS [3]. Approximately $85-90 \%$ of MS patients present with relapsing-remitting multiple sclerosis (RRMS) type, which is characterized by relapsing of new neurological symptoms [4]. MS is identified by various sets of symptoms, which can 
cause serious physical and mental problems and deteriorate cognitive function [5,6]. The main symptoms in MS are predominantly sensory problems, motor weakness, blurred vision, diplopia, and genitourinary problems which can affect patients' quality of life (QoL) [7]. QoL is defined as a subjective satisfaction with life [8], and health-related quality of life (HQoL) has been considered to be the capacity to obtain satisfaction from significant behavior despite one's disease [9]. HQoL is important for measuring the impact of chronic diseases such as MS [10]. According to World Health Organization, QoL is not only not feeling ill, but also having a sense of physical, mental and social well-being. With excluding cultural, economic and other aspects of QoL, HQoL is the main concern in the healthcare system [11], although when a patient is ill, almost all aspects of life can become healthrelated [12].

A study of assessing HQoL in the early stages of MS demonstrated similar QoL of MS patients, as the general adult population [13]. A clinical trial of assessing HQoL in patients with RRMS found that HQoL didn't change over the first year of therapy [14]. On the other hand, a large cohort of 1,157 untreated patients whit RRMS found an impairment in HQoL of patients in the early stages of MS [15]. United States Food and Drug Administration approved three groups of medication, include injectable, oral and infused medicines for MS. The number of disease-modifying drugs (DMDs) for the treatment of MS, especially oral forms, have increased noticeably in recent years. DMDs can boost patients' HQoL by reducing number of relapses and decreasing disease activity. Also, complications of repeated injections like skin reactions at injection sites or side effects of oral medications such as gastrointestinal problems [16] may have a negative effect on patients' HQoL. Repeatedly injections treatments can give rise to restrictions in everyday life, and make the patients worried of their chronic disease. So, both benefits and side effects of drugs can affect HQoL, and it is an efficient measure for healthcare providers to evaluate the treatment and disease progression $[17,18]$.

Impacting factors on MS patients' HQoL, such as demographic factors, disease duration, the severity of the disease and frequency of relapse, have assessed in recent years, which is sometimes ac- companied by conflicting results [19-22]. Furthermore, there is a gap in the literature regarding the assessment of the impact of the type of DMDs on QoL in MS patients. The primary aim of this study is to compare the association of oral and injection drug groups whit HQoL in RRMS. Investigating the relation between age, gender, duration of disease, number of relapses, disease severity and HQoL are other goals of this study.

\section{METHODS}

\section{Study design}

This is an observational cross-sectional study from October 2019 to February 2020. Patients were recruited via the neurology department at the university hospital. The study protocol reviewed and approved by the ethics committee, according to the declaration of Helsinki [23]. All of the patients involved in the study signed a detailed informed consent before filling the questionnaire and the study did not impose a financial burden on patients. All patients were graded by a neurologist according to the expanded disability status scale (EDSS) [24]. According to the declaration of Helsinki, the Ethics committee of Tabriz University of Medical Science reviewed and approved the study protocol (Ethics Code: IR.TBZMED.REC.1398.865)

\section{Study population}

Inclusion criteria were; definitive diagnosis of RRMS according to McDonald (2017 revised) diagnostic criteria [25], a lower degree of disability RRMS whit the EDSS score $\leq 4$, Usage of one of the DMDs against MS and age above 18. Exclusion criteria were the EDSS score $>4$, other conditions which can affect HQoL include pregnancy, psychiatric disorder, diabetes, cancer, rheumatological and hematological disease, history of alcohol abuse, receive of corticosteroid pulse or MS relapse within 8 weeks of assessment, systemic diseases or severe disabilities, presence of physical impairments that could interfere with QoL testing. Also, progressive forms of the disease (primary and secondary progressive MS) and clinically isolated syndrome excluded.

According to drug usage, we divided patients into two groups of oral and injection medications. Oral drug group included dimethyl fumarate, 240 
$\mathrm{mg}$ capsule twice a day, and fingolid, $0.5 \mathrm{mg}$ capsule, once per day. Injection group included high dose high-frequency drugs (Interferon beta-1a) three times per week, subcutaneous injection; glatiramer acetate every other day, subcutaneous injection, low dose, low-frequency drugs (Interferon beta-1a) once per week, intramuscular injection; natalizumab $300 \mathrm{mg}$, every 28 days, intravenous infusion and rituximab $500 \mathrm{mg}$ once per 6 months, intravenous infusion. Also, the Injection medicine group divided into two subgroups of injectable and infused drugs.

\section{Measuring HQoL}

We used the Persian version of multiple sclerosis quality of life-54 (MSQOL-54) questionnaire, designed by Vickrey et al. [26-28], for measuring HQoL. With adding 18 MS-specific items to the short-form 36 health survey questionnaire (SF-36), MSQOL-54 combines both generic and MS-specific items into a single instrument. The validity and reliability of the Persian translated version of questionnaire approved by Ghaem et al. [29]. Physical function, health perceptions, energy/fatigue, role limitations due to physical problems, pain, sexual function, social function and health distress are subscales of physical health composite of MSQOL-54. Overall quality of life, emotional well-being, role limitations due to emotional problems, cognitive function and health distress are subscales of mental health composite. Health distress is the only subscale which is common in both mental and physical health overall scores. Combinations of subscale scores according to the instrument [30] provides two scores for mental and phys- ical health. Composite scores range from 0 to 100 , which means full health. A printed version of the questionnaire filled by patients and in case of disability a trained colleague help patients in reading or filling. All patients were in the same place with the same condition, without any limitation in time, to fill it carefully.

\section{Statistical analyzes}

Analyze conducted by IBM SPSS Statistics 26.0 (SPSS Inc., Chicago, IL, USA) with a 0.05 level of significance and $95 \%$ confidence interval (CI). Values are given as mean \pm standard deviation cut to two decimal places. Inferential statistics including the independent sample T-test, Pearson correlation were used to evaluate the data. Also, regression analysis was performed to determine the possible confounders.

\section{RESULTS}

\section{Demographic and clinical data}

The descriptive statistics for both oral and injection groups are presented in Table 1.115 patients include 34 (29.6\%) males and 81 (70.4\%) females with the mean age of $33.06 \pm 8.68$ years old, ranging from 18 to 54 years old, involved in the study. Regarding education, $15.6 \%$ of patients had the education level $<12$, and in $84.4 \%$ of patients, the education level was $\geq 12$. The range of the EDSS score was from 0 to 4 (mean EDSS, $1.08 \pm 1.12$ ); it was $\leq 1$ in $66.9 \%$ of patients. Regarding the frequency of relapse, $71.4 \%$ of patients had $\leq 2$ relapses during disease duration. As shown in table 1, 46.1\% $(n=53)$ of patients were under oral drugs and $53.9 \%$

TABLE 1. Demographic factors and clinical characteristics of the patients

\begin{tabular}{|c|c|c|c|c|c|c|c|}
\hline \multirow{2}{*}{ Characteristics } & \multirow{2}{*}{ Total } & \multirow{2}{*}{ Oral } & \multirow{2}{*}{ Injection } & \multirow{2}{*}{$P$ value } & \multicolumn{3}{|c|}{ Injection } \\
\hline & & & & & Injectable & Infused & P-value \\
\hline $\begin{array}{l}\text { Number of patients } \\
\text { (male:female) }\end{array}$ & $115(34: 81)$ & $\begin{array}{c}53(46.1 \%) \\
(21: 32)\end{array}$ & $\begin{array}{c}62(53.9 \%) \\
(13: 49) \\
\end{array}$ & & $\begin{array}{c}41(66.1 \%) \\
(6: 35) \\
\end{array}$ & $\begin{array}{c}21(33.9 \%) \\
(7: 14)\end{array}$ & \\
\hline Age & $33.06 \pm 8.68$ & $32.13 \pm 8.84$ & $33.85 \pm 8.55$ & 0.29 & $32.97 \pm 8.64$ & $35.57 \pm 8.30$ & 0.26 \\
\hline Education & $13.09 \pm 3.26$ & $13.62 \pm 3.02$ & $12.64 \pm 3.40$ & 0.12 & $13.72 \pm 2.80$ & $10.52 \pm 3.54$ & 0.00 \\
\hline EDSS score & $1.08 \pm 1.12$ & $1.08 \pm 0.99$ & $\begin{array}{l}1.08 \pm \\
1.22\end{array}$ & 0.98 & $0.76 \pm 1.04$ & $1.71 \pm 1.34$ & 0.00 \\
\hline Disease dation (months) & $76 \pm 65.46$ & $79.41 \pm 64.49$ & $73.08 \pm 66.67$ & 0.60 & $65.46 \pm 65.89$ & $\begin{array}{c}87.95 \pm \\
67.25 \\
\end{array}$ & 0.21 \\
\hline frequency of relapses & $2.27 \pm 3.05$ & $2.26 \pm 3.30$ & $2.29 \pm 2.84$ & 0.96 & $1.70 \pm 2.74$ & $3.42 \pm 2.76$ & 0.23 \\
\hline
\end{tabular}

EDSS: expanded disability status scale 
$(\mathrm{n}=62)$ were under injectable drugs. There was no significant difference in demographics factors between two groups. Then injection group divided in two subgroups; injectable $(\mathrm{n}=41)$ and infused $(\mathrm{n}=21)$. As shown in table 1 , there was no significant difference in the age, disease duration and frequency of relapses between two subgroups, but education levels and the EDSS scores had a significant difference between two subgroups.

\section{Comparing HQoL between two groups}

Table 2 is a summary of the mean scores of HQoL subscales in total and groups. Also, subscale scores in percent have been shown in figure 1, which shows that the difference is not significant in any subscale of HQoL in our sample. The physical function subscale was the most different one, between all of the subscales. $14.08 \pm 3.55$ was the mean score of oral medicine group while the injection group's mean score was $12.88 \pm 4.11$; nevertheless, this difference was not statistically significant $(p=0.09)$. Without significant difference $(p>$ 0.05 ), the mean scores of physical subscales of
HQoL, including health perceptions, energy/fatigue, physical role limitations and sexual function, were slightly higher in oral group comparing to injection group. Oral and injection DMDs showed a similar function in reducing the pain of RRMS patients in our sample. Social function subscale scores showed the least difference between two groups $(8.84 \pm 2.29$ versus $8.83 \pm 2.38 ; \mathrm{p}=0.98)$. Health distress, as the only subscale which is common in mental and physical HQoL, was not different, too $(p=0.84)$. Generally, there was no statistically difference between two groups of patients but oral medicines showed a better function in physical health composite and injection DMDs were better in mental health composite. Despite the confounder factors, the comparison of injectable and infused subgroups showed no difference in any subscale of HQoL, too.

Relations between demographic characteristics of patients and HQoL

Table 3 is a summary of correlation coefficients of demographic characteristics and HQoL subscales. According to our results, there was a nega-

TABLE 2. QoL subscales comprise between drug groups

\begin{tabular}{|c|c|c|c|c|c|c|c|c|}
\hline \multirow{2}{*}{\multicolumn{2}{|c|}{ HQoL subscales }} & \multirow{3}{*}{$\begin{array}{c}\text { Total } \\
13.44 \pm \\
3.89\end{array}$} & \multirow{3}{*}{$\begin{array}{c}\text { Oral } \\
14.08 \pm \\
3.55\end{array}$} & \multirow{3}{*}{$\begin{array}{c}\text { Injection } \\
12.88 \pm 4.11\end{array}$} & \multirow{3}{*}{$\begin{array}{c}\text { P value } \\
0.09\end{array}$} & \multicolumn{3}{|c|}{ Injection } \\
\hline & & & & & & \multirow{2}{*}{$\begin{array}{c}\text { Injectable } \\
13.45 \pm 3.78\end{array}$} & \multirow{2}{*}{$\begin{array}{c}\text { Infused } \\
11.77 \pm \\
4.57\end{array}$} & \multirow{2}{*}{$\begin{array}{c}\text { P-value } \\
0.13\end{array}$} \\
\hline Physical & $\begin{array}{l}\text { physical function } \\
\text { (max:17) }\end{array}$ & & & & & & & \\
\hline & $\begin{array}{l}\text { Health perceptions } \\
\text { (max:17) }\end{array}$ & $\begin{array}{c}10.73 \pm \\
3.18 \\
\end{array}$ & $\begin{array}{c}11.08 \pm \\
3.03 \\
\end{array}$ & $10.44 \pm 3.31$ & 0.28 & $10.51 \pm 3.52$ & $\begin{array}{c}10.32 \pm \\
2.92 \\
\end{array}$ & 0.83 \\
\hline & Energy/fatigue (max:12) & $6.66 \pm 2.14$ & $6.69 \pm 2.08$ & $6.63 \pm 2.21$ & 0.88 & $6.60 \pm 2.32$ & $6.69 \pm 2.03$ & 0.87 \\
\hline & $\begin{array}{l}\text { Physical role limitations } \\
\text { (max:12) }\end{array}$ & $8.24 \pm 4.59$ & $7.98 \pm 4.77$ & $8.46 \pm 4.46$ & 0.57 & $8.19 \pm 4.45$ & $9.00 \pm 4.54$ & 0.50 \\
\hline & Pain (max:11) & $8.23 \pm 2.34$ & $8.17 \pm 2.60$ & $8.29 \pm 2.13$ & 0.78 & $8.35 \pm 2.11$ & $8.18 \pm 2.19$ & 0.76 \\
\hline & Sexual function (max:8) & $6.25 \pm 2.22$ & $6.68 \pm 1.97$ & $5.94 \pm 2.36$ & 0.13 & $6.15 \pm 2.30$ & $5.46 \pm 2.50$ & 0.35 \\
\hline & Social function (max:12) & $8.84 \pm 2.33$ & $8.84 \pm 2.29$ & $8.83 \pm 2.38$ & 0.98 & $9.09 \pm 2.25$ & $8.33 \pm 2.59$ & 0.23 \\
\hline & Health distress (max:11) & $7.49 \pm 2.82$ & $7.55 \pm 2.69$ & $7.45 \pm 2.95$ & 0.84 & $7.29 \pm 3.16$ & $7.75 \pm 2.56$ & 0.57 \\
\hline \multirow[t]{5}{*}{ Mental } & $\begin{array}{l}\text { Overall quality of life } \\
\text { (max:18) }\end{array}$ & $\begin{array}{c}12.99 \pm \\
3.40 \\
\end{array}$ & $\begin{array}{c}12.70 \pm \\
3.72 \\
\end{array}$ & $13.25 \pm 3.10$ & 0.38 & $13.50 \pm 2.98$ & $\begin{array}{c}12.75 \pm \\
3.43 \\
\end{array}$ & 0.37 \\
\hline & $\begin{array}{l}\text { Emotional well-being } \\
\text { (max:29) }\end{array}$ & $\begin{array}{c}16.83 \pm \\
5.45 \\
\end{array}$ & $\begin{array}{c}16.74 \pm \\
5.51 \\
\end{array}$ & $16.91 \pm 5.44$ & 0.86 & $16.94 \pm 5.93$ & $\begin{array}{c}16.84 \pm \\
4.48 \\
\end{array}$ & 0.94 \\
\hline & $\begin{array}{l}\text { Mental role limitations } \\
\text { (max:24) }\end{array}$ & $\begin{array}{l}15.30 \pm \\
9.62 \\
\end{array}$ & $\begin{array}{l}15.39 \pm \\
9.77 \\
\end{array}$ & $15.22 \pm 9.57$ & 0.92 & $14.24 \pm 9.71$ & $\begin{array}{c}17.14 \pm \\
9.22 \\
\end{array}$ & 0.26 \\
\hline & $\begin{array}{l}\text { Cognitive function } \\
\text { (max:15) }\end{array}$ & $\begin{array}{l}10.85 \pm \\
3.25 \\
\end{array}$ & $\begin{array}{c}10.13 \pm \\
3.21 \\
\end{array}$ & $11.46 \pm 3.18$ & 0.28 & $11.79 \pm 3.29$ & $\begin{array}{c}10.82 \pm \\
2.91 \\
\end{array}$ & 0.25 \\
\hline & Health distress (max:14) & $9.54 \pm 3.59$ & $9.61 \pm 3.41$ & $9.48 \pm 3.76$ & 0.84 & $9.28 \pm 4.02$ & $9.86 \pm 3.26$ & 0.57 \\
\hline \multirow[t]{2}{*}{$\begin{array}{l}\text { Overall } \\
\text { scores }\end{array}$} & $\begin{array}{l}\text { Physical health composite } \\
\text { (max:100) }\end{array}$ & $\begin{array}{c}69.79 \pm \\
16.63 \\
\end{array}$ & $\begin{array}{c}70.59 \pm \\
16.73 \\
\end{array}$ & $\begin{array}{c}69.10 \pm \\
16.65 \\
\end{array}$ & 0.63 & $69.98 \pm 16.66$ & $\begin{array}{c}67.40 \pm \\
16.93 \\
\end{array}$ & 0.56 \\
\hline & $\begin{array}{l}\text { Mental health composite } \\
\text { (max:100) }\end{array}$ & $\begin{array}{l}65.54 \pm \\
19.86\end{array}$ & $\begin{array}{l}64.61 \pm \\
20.98\end{array}$ & $\begin{array}{c}66.34 \pm \\
19.00\end{array}$ & 0.64 & $65.78 \pm 20.18$ & $\begin{array}{c}67.43 \pm \\
16.87\end{array}$ & 0.74 \\
\hline
\end{tabular}

HQoL; Health-related Quality of Life; Max: maximum score 


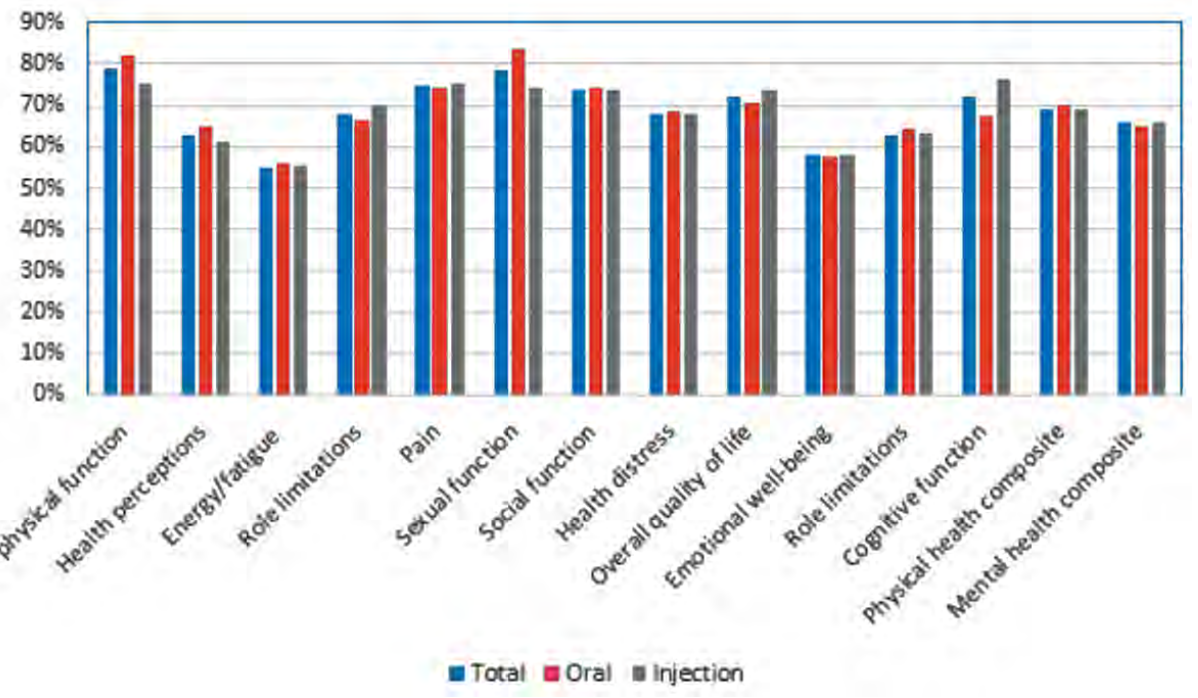

FIGURE 1. QoL subscale scores in total and between drug groups (amounts in percent)

tive correlation between age $(\mathrm{p}<0.05)$ and the EDSS $(p<0.01)$ with physical health composite, but education had a positive correlation with physical health composite $(\mathrm{p}<0.05)$. Getting older worsened physical function $(\mathrm{p}<0.01)$ and health perception $(p<0.05)$ subscales, but it couldn't impair any score of mental health subscales. A positive relationship between education and physical function ( $\mathrm{p}<0.01$ ), health perception, sexual function, social function and health distress was observed $(\mathrm{p}<0.05)$. Also, the EDSS score had a negative impact on physical function, health perception, pain, and social function, health distress, mental overall quality of life, cognitive function $(\mathrm{p}<0.01)$, physical role limitation and sexual function $(p<$ $0.05)$ subscales. There was a negative relation between the duration of the disease and physical function $(p<0.01)$ and social function $(p<0.05)$ subscales. With increasing in number of relapses, scores of physical function and health perceptions subscales decreased significantly $(\mathrm{p}<0.05)$. None of the mental health subscales affected by the duration of the disease and number of relapses in our sample.

TABLE 3. Correlation coefficient between demographic factors and clinical characteristics of patients and QoL subscale (Pearson correlation)

\begin{tabular}{|c|c|c|c|c|c|c|}
\hline \multirow{2}{*}{\multicolumn{2}{|c|}{ HQoL subscales }} & \multicolumn{5}{|c|}{ Demographic characteristics } \\
\hline & & \multirow{2}{*}{$\begin{array}{c}\text { Age } \\
-0.40 * *\end{array}$} & \multirow{2}{*}{$\begin{array}{c}\text { Education } \\
0.29 * *\end{array}$} & \multirow{2}{*}{$\begin{array}{c}\text { EDSS score } \\
-0.54^{* *}\end{array}$} & \multirow{2}{*}{$\begin{array}{c}\text { Duration } \\
-0.29 * *\end{array}$} & \multirow{2}{*}{$\begin{array}{c}\begin{array}{c}\text { Number of } \\
\text { relapses }\end{array} \\
-0.20^{*}\end{array}$} \\
\hline \multirow[t]{8}{*}{ Physical } & Physical function & & & & & \\
\hline & Health perceptions & $-0.22 *$ & $0.22 *$ & $-0.41 * *$ & -0.13 & $-0.20 *$ \\
\hline & Energy/fatigue & 0.01 & -0.13 & -0.16 & 0.02 & -0.03 \\
\hline & Physical role limitations & -0.11 & 0.04 & $-0.23 *$ & -0.05 & -0.03 \\
\hline & Pain & -0.18 & 0.14 & $-0.27^{* *}$ & -0.09 & -0.17 \\
\hline & Sexual function & -0.14 & $0.28 *$ & $-0.24 *$ & -0.11 & 0.00 \\
\hline & Social function & -0.16 & $0.20 *$ & $-0.28 * *$ & $-0.19 *$ & -0.15 \\
\hline & Health distress & -0.09 & $0.22 *$ & $-0.27 * *$ & 0.02 & -0.03 \\
\hline \multirow[t]{5}{*}{ Mental } & Overall quality of life & -0.07 & 0.15 & $-0.25 * *$ & -0.14 & -0.16 \\
\hline & Emotional well-being & 0.00 & 0.15 & -0.15 & -0.03 & -0.08 \\
\hline & Mental role limitations & 0.12 & 0.02 & -0.10 & 0.07 & -0.00 \\
\hline & Cognitive function & -0.17 & 0.16 & $-0.25 * *$ & -0.11 & -0.02 \\
\hline & Health distress & -0.09 & $0.22 *$ & $-0.27 * *$ & 0.02 & -0.03 \\
\hline \multirow{2}{*}{$\begin{array}{l}\text { Overall } \\
\text { scores }\end{array}$} & Physical health composite & $-0.23 * *$ & $0.22 *$ & $-0.45^{* *}$ & -0.15 & -0.15 \\
\hline & Mental health composite & 0.00 & 0.12 & 0.01 & -0.00 & -0.06 \\
\hline
\end{tabular}

HQoL: health-related quality of life; EDSS: expanded disability status scale; $* * p$ value $<0.01 ; * p$ value $<0.05$ 
TABLE 4. Gender differences in demographic characteristics and subscales of QoL

\begin{tabular}{|c|c|c|c|c|}
\hline \multicolumn{2}{|c|}{ Demographic characteristics } & \multirow{2}{*}{$\begin{array}{c}\text { Female }(\mathbf{n}=\mathbf{8 1}) \\
33.40 \pm 8.31\end{array}$} & \multirow{2}{*}{$\begin{array}{c}\text { Male }(\mathbf{n}=\mathbf{3 4}) \\
32.23 \pm 9.61\end{array}$} & \multirow{2}{*}{$\begin{array}{c}\text { P value } \\
0.51 \\
\end{array}$} \\
\hline & Age & & & \\
\hline & Education & $13.30 \pm 3.20$ & $12.61 \pm 3.40$ & 0.32 \\
\hline & Duration (month) & $73.24 \pm 58.04$ & $82.55 \pm 81.09$ & 0.48 \\
\hline & Number of relapses & $2.28 \pm 3.36$ & $2.26 \pm 2.17$ & 0.97 \\
\hline & EDSS & $1.06 \pm 1.13$ & $1.13 \pm 1.10$ & 0.78 \\
\hline \multicolumn{5}{|c|}{ HQoL subscales } \\
\hline \multirow[t]{8}{*}{ Physical } & physical function (max:17) & $13.36 \pm 3.86$ & $13.62 \pm 4.01$ & 0.74 \\
\hline & Health perceptions (max:17) & $10.68 \pm 3.12$ & $10.87 \pm 3.37$ & 0.76 \\
\hline & Energy/fatigue (max:12) & $6.58 \pm 2.07$ & $6.83 \pm 2.33$ & 0.58 \\
\hline & Physical role limitations (max:12) & $8.33 \pm 4.59$ & $8.02 \pm 4.65$ & 0.74 \\
\hline & Pain (max:11) & $8.08 \pm 2.40$ & $8.60 \pm 2.20$ & 0.28 \\
\hline & Sexual function (max:8) & $6.32 \pm 2.16$ & $6.06 \pm 2.43$ & 0.63 \\
\hline & Social function (max:12) & $8.77 \pm 2.32$ & $9.00 \pm 2.37$ & 0.64 \\
\hline & Health distress (max:11) & $7.49 \pm 2.62$ & $7.50 \pm 3.29$ & 0.98 \\
\hline \multirow[t]{5}{*}{ Mental } & Overall quality of life (max:18) & $13.11 \pm 3.24$ & $12.72 \pm 3.77$ & 0.57 \\
\hline & Emotional well-being (max:29) & $16.56 \pm 5.11$ & $17.46 \pm 6.23$ & 0.42 \\
\hline & Mental role limitations (max:24) & $15.30 \pm 9.39$ & $15.29 \pm 10.30$ & 0.99 \\
\hline & Cognitive function (max:15) & $11.25 \pm 3.26$ & $9.88 \pm 3.06$ & $0.03 *$ \\
\hline & Health distress (max:14) & $9.54 \pm 3.33$ & $9.53 \pm 4.18$ & 0.98 \\
\hline \multirow[t]{2}{*}{ Overall scores } & Physical health composite (max:100) & $69.62 \pm 16.19$ & $70.20 \pm 17.88$ & 0.86 \\
\hline & Mental health composite (max:100) & $65.80 \pm 19.11$ & $64.93 \pm 21.84$ & 0.83 \\
\hline
\end{tabular}

EDSS: expanded disability status scale; HQoL: health-related quality of life; Max: maximum score; * $p$ value $<0.05$

Table 4 is a summary of gender differences. There wasn't any significant difference between other demographic characteristics of patients between male and female patients. Cognitive function is the only subscale in which gender differences are significant and females with the mean score of $11.25 \pm 3.26$ score had a better function in comprising to males with the mean score of $9.88 \pm 3.06$ $(\mathrm{p}=0.03)$ and mental role limitations showed the least difference $(15.30 \pm 9.39$ in female and $15.29 \pm$ 10.30 on male; $p$ value 0.99 ).

\section{DISCUSSION}

This study aimed to describe the QoL in patients with RRMS receiving oral DMDs and in a similar group of MS patients with injection DMDs. In the present study, for the first time, we assessed the influence of the type of DMDs on HQoL in MS patients. We found no differences between two groups and subgroups of the study in any subscale of HQoL. Naturally, patients who get infused medications, include natalizumab and rituximab, had a worse condition in the severity of disease and this can affect our analyzes of comparing two subgroups of injection drugs. Also, there is a meaningful difference in the education of patients of sub- groups, which can affect HQoL [20]. The DMDs efficacy in improving the condition of patients by reducing the number of relapses and preventing disease progression can affect HQoL. Also, the side effects of medications are an important factor in this field. According to recent studies, in similar conditions, oral medicines are preferred by patients $[31,32]$. Whit considering all of these, the results of our study suggested that oral and injection medications have a similar effect on HQoL of lower degree of disability in RRMS patients.

A lower level of HQoL in MS patients in comparing to the general population and other chronic disorders, such as epilepsy and Parkinson's disease, reported in recent studies [33-35]. DMDs was associated with a slower deterioration of HQoL [36]. A cross-sectional study done by Isaksson et al. with assessing the HQoL with SF-36 questionnaire found there is no significant differences between the MS patients receiving parenteral treatment and in a similar untreated group. Treated group had better HQoL scores than untreated group with respect to emotional role, physical role and social function, but the difference was not significant [37].

Recent studies found that HQoL is associated with the EDSS scores and number of relapses [3840]. Whit including patients whit the EDSS score $\leq 4$, 
severe MS patients exclude from our sample. Even in the first stages of the disease, the EDSS has a significant negative effect on physical health but not mental health. Also, we found no relation between duration of disease whit composite HQoL scores which means prolonged illness cannot make patients' HQoL worse, if it doesn't make the disease more severe. In Yalachkov et al. report, duration of disease was associated with the lower levels of QoL [20].

Generally, physical health is more correlated to the demographic characteristics of the patients, in comprise to mental health. Education had a positive effect on almost all of the HQoL subscales. Unlike the current idea [20] and a positive correlation in our sample, the effect of education on mental health was not statistically significant. Even though all of our patients were adults between 18 to 54 years old, getting old had an impact on physical health, but not mental health. Older patients felt more pain and their cognitive function was worse, whether these relations were not statistically significant in our sample.

MS prevalence in females is more than males [41,42]. A study of gender differences in MS patients in Italy found a stronger impact of disability in men [43]. Whit comparing genders in our sample, we found no difference in none of the subscales of HQoL but cognitive function. Assessing gender differences in cognition is a controversial line of research [44], but our results showed a better cognitive function in females. For achieving a reliable result, cognitive tests needed and we can-

\section{REFERENCES}

1. Reich DS, Lucchinetti CF, Calabresi PA. Multiple Sclerosis. N Engl J Med. 2018;378(2):169-80.

2. Kingwell E, Marriott JJ, Jetté N, Pringsheim T, Makhani N, Morrow $\mathrm{SA}$, et al. Incidence and prevalence of multiple sclerosis in Europe: A systematic review. BMC Neurol. 2013;13:128-.

3. Milo R, Kahana E. Multiple sclerosis: geoepidemiology, genetics and the environment. Autoimmunity Reviews. 2010;9(5):A387-A94.

4. McKay KA, Kwan V, Duggan T, Tremlett H. Risk factors associated with the onset of relapsing-remitting and primary progressive multiple sclerosis: A systematic review. BioMed Research International. 2015;2015:817238

5. Talebi M, Nikanfar M, Sorkhabi R, Sharifipour E, Bahrebar M, Kiavar A, et al. Optic coherence tomography findings in relapsing-remitting multiple sclerosis patients of the northwest of Iran. Iranian Journal of Neurology. 2013;12(3):81

6. Talebi M, Majdi A, Kamari F, Sadigh-Eteghad S. The Cambridge Neuropsychological Test Automated Battery (CANTAB) Versus the Minimal Assessment of Cognitive Function in Multiple Sclerosis (MACFIMS) for the Assessment of Cognitive Function in Patients not conclude about cognitive function, just with a few questions.

About 30\% prevalence for depression and about $20 \%$ for anxiety have been reported in recent studies between MS patients [45]. Psychiatric comorbidities like depression, anxiety, alcohol abuse and bipolar disorder are associated with lower HQoL, greater levels of fatigue, and reduced adherence to DMDs $[46,47]$. For removing this confounder factors, we exclude patients whit history of phycological comorbidities, from our sample. The scores of oral and injection drug users showed no difference in the mental health condition of patients and drug groups were almost similar in preventing psychiatric comorbidities due to MS.

\section{CONCLUSIONS}

Oral and injection DMDs have a similar function in boosting patients' HQoL. Getting older and increasing the severity of the disease have a negative effect on HQoL, but more degree of education can make it better. Despite the more prevalence of MS in females, there is no association between gender and HQoL in a lower degree of disability of RRMS patients.

\section{Acknowledgements}

We would like to thank the patients involved in the study. Also, we thank Neuroscience Research Center of Tabriz University of medical science, for their kind support.

Conflict of interest: none declared Financial support: none declared

with Multiple Sclerosis. Multiple Sclerosis and Related Disorders. 2020:102172.

7. Janssens A. Van doorn PA, De boer JB, Kalkers NF, van der Meche FG, Passchier J, et al. Anxiety and depression influence the relation between disability status and quality of life in multiple sclerosis. Mult Scler. 2003;9(4):397-403.

8. Phennings LE, Polman C, Van der Ploeg H. Quality of life in multiple sclerosis. MS Management. 1995;2(1):26-30.

9. Meyers AR, Gage H, Hendricks A. Health-related quality of life in neurology. Archives of Neurology. 2000;57(8):1224-7.

10. Erickson P, Patrick D. Health status and health policy: quality of life in health care evaluation and resource allocation: Oxford University Press New York; 1993.

11. Sivertsen H, Bjørkløf GH, Engedal K, Selbæk G, Helvik AS. Depression and Quality of Life in Older Persons: A Review. Dementia and Geriatric Cognitive Disorders. 2015;40(5-6):311-39.

12. Guyatt $\mathrm{GH}$, Feeny $\mathrm{DH}$, Patrick DL. Measuring health-related quality of life. Annals of Internal Medicine. 1993;118(8):622-9. 
13. Duka Glavor K, Titlić M, Vuletic G. Quality of life and health of patients in early stages of Multiple sclerosis. Psychiatr Danub. 2019;31(Suppl 1):118-25.

14. Pakdaman H, Amini Harandi A, Gharagozli K, Abbasi M, Tabassi A, Ashrafi $F$, et al. Health-related quality of life in patients with relapsing-remitting multiple sclerosis treated with subcutaneous interferon $\beta$-1a in Iran. Int J Neurosci. 2017;127(6):501-7.

15. Putzki N, Fischer J, Gottwald K, Reifschneider G, Ries S, Siever A, et al. Quality of life in 1000 patients with early relapsing-remitting multiple sclerosis. Eur J Neurol. 2009;16(6):713-20.

16. Wang G, Marrie RA, Fox RJ, Tyry T, Cofield SS, Cutter GR, et al. Treatment satisfaction and bothersome bladder, bowel, sexual symptoms in multiple sclerosis. Mult Scler Relat Disord. 2018;20:1621.

17. Jongen PJ. Health-related quality of life in patients with multiple sclerosis: impact of disease-modifying drugs. CNS Drugs. 2017;31(7):585-602.

18. Baumstarck K, Boyer L, Boucekine M, Michel P, Pelletier J, Auquier $P$. Measuring the quality of life in patients with multiple sclerosis in clinical practice: A necessary challenge. Multiple Sclerosis International. 2013;2013.

19. Santos M, Sousa C, Pereira M, Pereira MG. Quality of life in patients with multiple sclerosis: A study with patients and caregivers. Disability and Health Journal. 2019;12(4):628-34.

20. Yalachkov Y, Soydaş D, Bergmann J, Frisch S, Behrens M, Foerch $\mathrm{C}$, et al. Determinants of quality of life in relapsing-remitting and progressive multiple sclerosis. Multiple Sclerosis and Related Disorders. 2019;30:33-7.

21. Gullo HL, Fleming J, Bennett S, Shum DH. Cognitive and physical fatigue are associated with distinct problems in daily functioning, role fulfilment, and quality of life in multiple sclerosis. Multiple Sclerosis and Related Disorders. 2019;31:118-23.

22. Malkova N, Riabukhina O, Babenko L, lonova T, Kishtovich A. Health-related quality of life in patients with multiple sclerosis. Zhurnal nevrologii i psikhiatrii imeni SS Korsakova. 2005;105(12):31.

23. Williams JR. The Declaration of Helsinki and public health. Bulletin of the World Health Organization. 2008;86:650-2.

24. Kurtzke JF. Rating neurologic impairment in multiple sclerosis: an expanded disability status scale (EDSS). Neurology. 1983;33(11):1444-.

25. Thompson AJ, Banwell BL, Barkhof F, Carroll WM, Coetzee T, Comi $\mathrm{G}$, et al. Diagnosis of multiple sclerosis: 2017 revisions of the McDonald criteria. The Lancet Neurology. 2018;17(2):162-73.

26. Vickrey B, Hays RD, Harooni R, Myers LW, Ellison GW. A health-related quality of life measure for multiple sclerosis. Quality of Life Research. 1995;4(3):187-206.

27. Heiskanen $S$, Meriläinen $P$, Pietilä AM. Health-related quality of life - testing the reliability of the MSQOL-54 instrument among MS patients. Scandinavian Journal of Caring Sciences. 2007;21(2):199206.

28. Miller A, Dishon S. Health-related quality of life in multiple sclerosis: Psychometric analysis of inventories. Multiple Sclerosis Journal. 2005;11(4):450-8.

29. Ghaem H, Haghighi AB, Jafari P, Nikseresht A. Validity and reliability of the Persian version of the multiple sclerosis quality of life questionnaire. Neurology India. 2007;55(4):369.

30. Vickrey BG, Hays RD, Harooni R, Myers LW, Ellison GW. A health-related quality of life measure for multiple sclerosis. Qual Life Res. 1995;4(3):187-206.

31. Osborne RH, De Abreu Lourenço R, Dalton A, Houltram J, Dowton D, Joshua $D E$, et al. Quality of life related to oral versus subcutaneous iron chelation: a time trade-off study. Value Health. 2007;10(6):451-6.
32. Holko P, Kawalec P, Mossakowska M. Quality of life related to oral, subcutaneous, and intravenous biologic treatment of inflammatory bowel disease: a time trade-off study. European Journal of Gastroenterology \& Hepatology. 2018;30(2):174-80.

33. Auty A, Belanger C, Bouchard J, Brunet D, Duquette P, Francis G, et al. Burden of illness of multiple sclerosis: Part II: Quality of life. Canadian Journal of Neurological Sciences. 1998;25(1):31-8.

34. Hermann BP, Vickrey B, Hays RD, Cramer J, Devinsky O, Meador K, et al. A comparison of health-related quality of life in patients with epilepsy, diabetes and multiple sclerosis. Epilepsy Research. 1996;25(2):113-8.

35. Riazi A, Hobart J, Lamping D, Fitzpatrick R, Freeman J, Jenkinson Caa, et al. Using the SF-36 measure to compare the health impact of multiple sclerosis and Parkinson's disease with normal population health profiles. Journal of Neurology, Neurosurgery \& Psychiatry. 2003;74(6):710-4.

36. Freeman J, Hobart J, Langdon D, Thompson A. Clinical appropriateness: a key factor in outcome measure selection: the 36 item short form health survey in multiple sclerosis. Journal of Neurology, Neurosurgery \& Psychiatry. 2000;68(2):150-6.

37. Isaksson A-K, Ahlström G, Gunnarsson L-G. Quality of life and impairment in patients with multiple sclerosis. Journal of Neurology, Neurosurgery \& Psychiatry. 2005;76(1):64-9.

38. Rudick RA, Miller DM. Health-related quality of life in multiple sclerosis. CNS Drugs. 2008;22(10):827-39.

39. Baumstarck K, Pelletier J, Butzkueven H, Fernandez O, Flachenecker $P$, Idiman $E$, et al. Health-related quality of life as an independent predictor of long-term disability for patients with relapsing-remitting multiple sclerosis. European Journal of Neurology. 2013;20(6):907-e79.

40. Vickrey BG, Lee L, Moore F, Moriarty P. EDSS change relates to physical $H R Q o L$ while relapse occurrence relates to overall $H R Q$ in patients with multiple sclerosis receiving subcutaneous interferon ß-1a. Multiple Sclerosis International. 2015;2015.

41. Azami M, YektaKooshali MH, Shohani M, Khorshidi A, Mahmudi L. Epidemiology of multiple sclerosis in Iran: A systematic review and meta-analysis. PloS One. 2019;14(4):e0214738.

42. Harbo HF, Gold R, Tintoré M. Sex and gender issues in multiple sclerosis. Therapeutic Advances in Neurological Disorders. 2013;6(4):237-48.

43. Casetta I, Riise T, Wamme Nortvedt M, Economou NT, De Gennaro $R$, Fazio $P$, et al. Gender differences in health-related quality of life in multiple sclerosis. Multiple Sclerosis (Houndmills, Basingstoke, England). 2009;15(11):1339-46.

44. Abraham A. Gender and creativity: an overview of psychological and neuroscientific literature. Brain Imaging Behav. 2016;10(2):609-18.

45. Boeschoten RE, Braamse AMJ, Beekman ATF, Cuijpers P, van Oppen P, Dekker J, et al. Prevalence of depression and anxiety in Multiple Sclerosis: A systematic review and meta-analysis. J Neurol Sci. 2017;372:331-41.

46. Marrie RA, Reingold S, Cohen J, Stuve O, Trojano M, Sorensen PS, et al. The incidence and prevalence of psychiatric disorders in multiple sclerosis: A systematic review. Mult Scler. 2015;21(3):30517.

47. Boeschoten RE, Braamse AM, Beekman AT, Cuijpers P, van Oppen $\mathrm{P}$, Dekker J, et al. Prevalence of depression and anxiety in multiple sclerosis: A systematic review and meta-analysis. Journal of the Neurological Sciences. 2017;372:331-41. 